\title{
Effect of chronic ethanol intake on lactase activity and active galactose absorption in rat small intestine
}

\author{
R MAZZANTI, E S DEBNAM, AND W J JENKINS \\ From the Department of Medicine and Department of Physiology, Royal Free Hospital School of Medicine, \\ London
}

SUMmARY The effects of feeding a nutritionally adequate liquid diet containing $5 \%$ ethanol to rats over a four week period on intestinal lactase activity and the kinetics of jejunal galactose absorption in vivo have been determined. Both lactase activity and the maximum capacity for active, saturable galactose absorption $\left(\mathrm{J}_{\max }\right)$ were increased significantly after chronic ethanol ingestion. In contrast, uptake of the sugar via the phlorhizin-insensitive (passive) route was unaffected by ethanol. Our results imply the presence of an increased maturity of the enterocyte population on the villus surface in response to ethanol. The relevance of this work to uptake studies in alcoholics is briefly discussed.

The acute exposure of the intestinal mucosa to ethanol results in structural damage ${ }^{1}$ and an impaired absorption of both nutrients ${ }^{2-4}$ and vitamins. $^{56}$ The malabsorption associated with chronic alcohol intake in man, however, does not appear to be related primarily to epithelial damage but rather is a consequence of an inadequate dietary intake. ${ }^{47}$

A recent study has shown a reduction in enterocyte turnover in rats after chronic ethanol ingestion. ${ }^{8}$ This may result in enterocytes residing longer on the villus surface producing an epithelium containing a greater proportion of mature cells. In order to examine this possibility, we have compared intestinal lactase activity in rats fed either a liquid diet containing ethanol or an isocaloric diet in which lipid was substituted for ethanol. Lactase activity can be considered a marker for enterocyte maturity. ${ }^{9}{ }^{10}$ Further information on the functional maturity of the intestinal mucosa after prolonged ethanol ingestion was obtained by measuring galactose uptake across the jejunum in vivo. As sugar uptake in vivo consists of both active and passive mechanisms ${ }^{11} 12$ galactose absorption was measured using a technique which allowed the kinetic parameters of apparent $\mathrm{K}_{\mathrm{t}}$ and maximum absorptive capacity $\left(\mathrm{J}_{\max }\right)$ of the active process to be obtained. ${ }^{11}$

Address for correspondence: Dr E S Debnam, Department of Physiology, Royal Free Hospital School of Medicine, Rowland Hill Street, London NW3 2PF.

Received for publication 2 May 1986.
A preliminary report of part of this work has been published. ${ }^{13}$

\section{Methods}

ANIMALS AND DIETS

Adult male Spraque-Dawley rats were individually caged at $21 \pm 1^{\circ} \mathrm{C}$ and pair fed for four to five weeks with a liquid diet containing Complan, casein, glucose, corn oil and Orovite 7, but in different proportions to provide $36 \%, 34 \%$, and $18 \%$ of the total calories as fat, glucose and protein respectively. ${ }^{14}$ The ethanol fed rats received a similar diet but ethanol $50 \mathrm{~g} / \mathrm{l}$ was substituted for fat to provide $36 \%$ of the total calories. The ethanol diet was replaced by the control diet $12 \mathrm{~h}$ before experimentation. Blood samples for the measurement of ethanol concentration ${ }^{15}$ were obtained from the tail vein immediately before absorption experiments.

\section{LACTASE ACTIVITY}

Mucosal scrapings were prepared from tissue samples trom both upper and lower regions of small intestine. Lactase activity (U/mg protein) was measured by the method of Dahlqvist. ${ }^{16}$ Protein concentrations were determined using bovine serum albumin as a standard. ${ }^{17}$

GALACTOSE ABSORPTION IN VIVO

Rats were anaesthetised with pentobarbitone sodium (90 mg/kg ip; Sagatal, May \& Baker Ltd). 
A section of the jejunum approximately $25 \mathrm{~cm}$ long beginning $2 \mathrm{~cm}$ from the ligament of Treitz was washed through with warm $\mathrm{NaCl}(154 \mathrm{mmol} / \mathrm{l})$ and cannulated at either end. The cannulae were connected to a fluid circuit through which bicarbonate saline ${ }^{18}$ warmed to $37^{\circ} \mathrm{C}$ and gassed with $95 \% \mathrm{O}_{2}$. $5 \% \mathrm{CO}_{2}(\mathrm{v} / \mathrm{v})$ was pumped at a flow rate of $2 \mathrm{ml} / \mathrm{min}$ using a peristaltic pump (Watson-Marlow England). The solution was recirculated for 20 minutes. Rectal temperature was maintained at $37^{\circ} \mathrm{C}$ throughout the experiment using a heated blanket with feedback control (BioScience Ltd, England). The kinetics of galactose uptake were determined by circulating increasing concentrations of the sugar (up to 64 $\mathrm{mmol} / \mathrm{l}$ ) dissolved in bicarbonate saline through the intestinal segment. All solutions were made to the same tonicity as described previously. ${ }^{11}$ After the circulation period, the sugar solution in the intestine and circulation system was washed out, diluted to a known volume and deproteined using $0.3 \mathrm{~N}$ barium hydroxide $/ 5 \%$ zinc sulphate. Galactose concentration was determined by a colormetric method. ${ }^{19}$ The segment of the intestine was removed and the length measured. Absorption of galactose at each concentration was calculated as luminal loss and expressed as $\mu \mathrm{mol} / 10 \mathrm{~cm} / 20 \mathrm{~min}$. The percentage absorption ranged from $19 \cdot 8 \%$ to $27 \cdot 5 \%$ of the amount circulated.

In separate experiments, the rate of galactose uptake at each initial concentration was corrected for passive, non-saturable transport using phlorhizin $\left(2 \cdot 10^{-3} \mathrm{M}\right)$. This concentration is the minimum necessary to abolish the galactose induced transmural potential difference measured in vivo. Subtraction of the amount of sugar absorbed in the presence of phlorhizin from that absorbed in its absence allowed an estimate of uptake via the active, saturable pathway. ${ }^{11}$ The kinetic parameters of apparent $\mathrm{K}_{\mathrm{t}}$ (an index of the affinity of the transport process for galactose) and $\mathrm{J}_{\max }$ (maximum absorptive capacity) were determined by Lineweaver-Burk analysis of the corrected absorption data.

\section{INTESTINAL HISTOLOGY AND MORPHOLOGY}

A $5 \mathrm{~cm}$ section of jejunum was removed from an unperfused region and cut longitudinally to form a flat sheet. The mucosal layer was removed by scraping with the edge of a glass microscope slide and weighed before and after drying to a constant weight at $70^{\circ} \mathrm{C}$. For measurements of villus height and enterocyte column size (the number of cells along one side of the villus), sections of jejunum 1 $\mathrm{cm}$ in length were removed and fixed in $10 \%$ formol saline. The tissue was blocked in paraffin wax, sectioned longitudinally $(5 \mu \mathrm{m})$ and stained with haemotoxylin and eosin. Villus height was measured using a microscope with an eyepiece graticule.

STATISTICAL ANALYSIS

All values are given as mean $\pm S E$. Differences between means were evaluated by Student's $t$ test for unpaired samples and considered not significant at $\mathrm{p}>0.05$.

\section{CHEMICALS}

D-galactose (glucose-free) and phlorhizin were obtained from Sigma UK Limited. All other chemicals were of Analar Grade from BDH Limited.

\section{Results}

Despite a daily ethanol intake of $14 \cdot 2 \pm 0 \cdot 3 \mathrm{~g} / \mathrm{kg}$ body weight the final body weights of rats on the ethanol diet $(284.8 \pm 32.4 \mathrm{~g})$ were very similar to those animals fed the control diet $(274 \cdot 2 \pm 27 \cdot 4 \mathrm{~g})$.

\section{INTESTINAL MORPHOLOGY AND HISTOLOGY}

The influence of ethanol ingestion on villus height, enterocyte column size and mucosal weights are shown in Table 1 . No significant changes in any of the parameters measured were observed.

\section{LACTASE ACTIVITY}

Mucosal lactase activity in the jejunal and ileal regions increased significantly by $142.4 \%(p<0.05)$ and $101.5 \%(p<0.05)$, respectively, after ethanol feeding (Fig. 1).

EFFECTS OF ETHANOL INGESTION ON THE KINETICS OF ACTIVE AND PASSIVE GALACTOSE ABSORPTION

In this study, the ethanol diet was withdrawn 12 hours before the absorption experiment in order to obtain comparable blood ethanol levels in all the alcohol fed rats $(1.91 \pm 0.47 \mathrm{mg} / 100 \mathrm{ml}(12))$.

Prior exposure to ethanol enhanced active galactose absorption at sugar concentrations of $4,8,16$,

Table 1 Mucosal wet and dry weights, villus height and enterocyte column size in jejunum from rats fed either a control diet or a 5\% ethanol diet. Results are given as mean $\pm S E$ with numbers of observations in brackets. NS not significant

\begin{tabular}{lcccc}
\hline & Control diet & \multicolumn{1}{l}{ Ethanol diet } \\
\hline $\begin{array}{l}\text { Mucosal wet } \\
\text { weight }(\mathrm{mg} / 5 \mathrm{~cm})\end{array}$ & $292 \cdot 9 \pm 19 \cdot 2$ & $(9)$ & $289 \cdot 7 \pm 30 \cdot 4$ & $(9) \mathrm{NS}$ \\
$\begin{array}{c}\text { Mucosal dry } \\
\text { weight }(\mathrm{mg} / 5 \mathrm{~cm})\end{array}$ & $89 \cdot 5 \pm 5 \cdot 5$ & $(9)$ & $87 \cdot 6 \pm 8 \cdot 7$ & $(9) \mathrm{NS}$ \\
$\begin{array}{l}\text { Villus height }(\mu \mathrm{m}) \\
\text { Enterocyte column size }\end{array}$ & $512 \cdot 5 \pm 13 \cdot 1$ & $(10)$ & $485 \cdot 3 \pm 28 \cdot 1(10) \mathrm{NS}$ \\
\hline
\end{tabular}




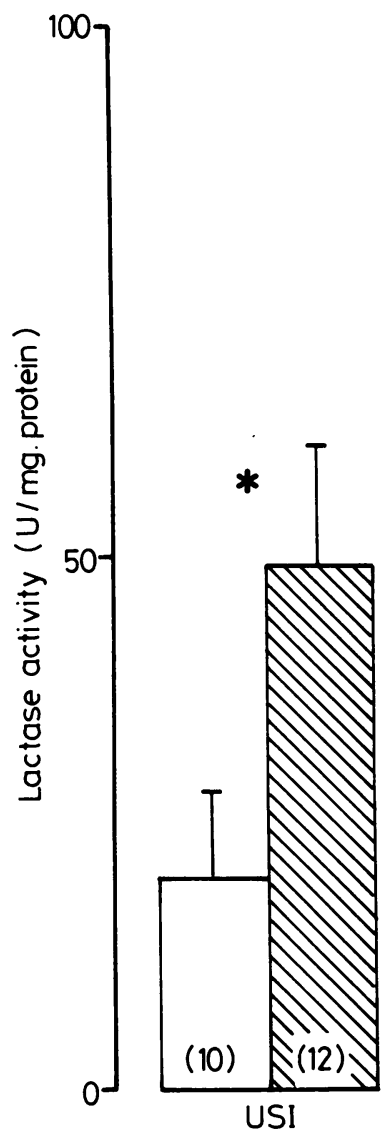

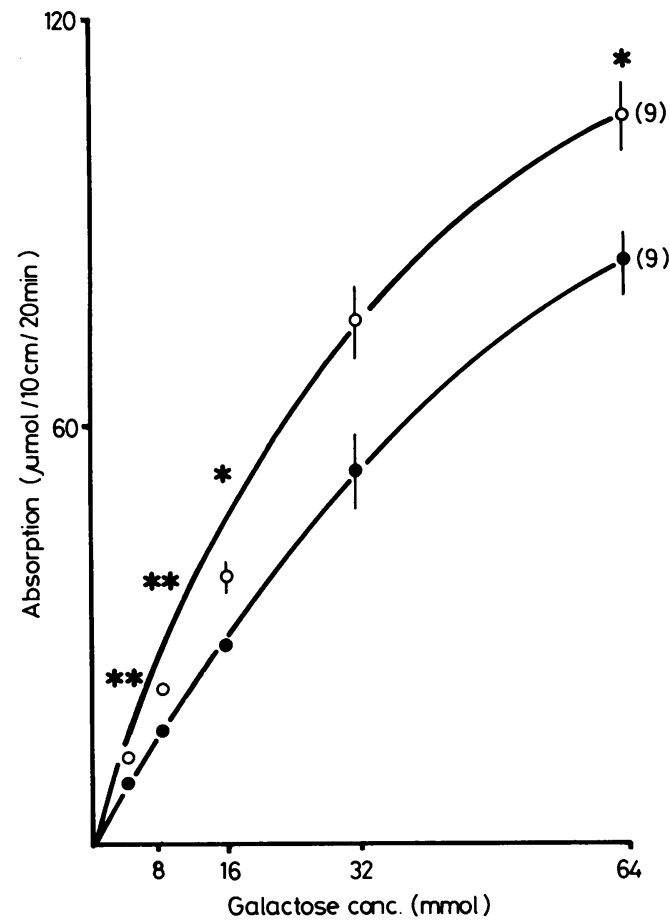

Fig. 2 Kinetics of galactose absorption measured in vivo after either a control diet (O) or a diet containing ethanol (O). Values have been corrected for the passive component of uptake (see text). Data are given as mean (SE indicated by vertical lines) with number of animals used in parentheses. ${ }^{*} p<0.025^{* *} p<0.005$.

Table 2 Effect of ethanol feeding on the kinetics of active galactose absorption across the rat jejunum. Results are given as mean $\pm S E$ with numbers of observations in brackets

\begin{tabular}{lll}
\hline & $K_{t}(\mathrm{mmol} / \mathrm{l})$ & $J_{\max }(\mu \mathrm{mol} / 10 \mathrm{~cm} / 20 \mathrm{~min})$ \\
\hline Control diet & $38 \cdot 7 \pm 3 \cdot 6(9)$ & $105 \cdot 9 \pm 8 \cdot 9(9)$ \\
Ethanol diet & $39 \cdot 4 \pm 2.5(9)$ & $132.5 \pm 6 \cdot 4(9)$ \\
\hline
\end{tabular}

and $64 \mathrm{mmol} / \mathrm{l}$ (Fig. 2). At $32 \mathrm{mmol} / \mathrm{l}$ the difference was not significant $(p>0 \cdot 05<0 \cdot 1)$ despite a $27 \cdot 1 \%$ increase in galactose uptake. Kinetic analysis of the corrected absorption data revealed an unchanged apparent $\mathrm{K}_{\mathrm{t}}$ but an increase of some $25 \cdot 1 \%$ in $\mathrm{J}_{\max }$ after the ethanol diet (Table 2).

In contrast with the effect of chronic ethanol on the active, saturable component of absorption, the rate of galactose uptake in the presence of phlorhizin was unaffected by alcohol. As an example, absorption from an initial sugar concentration of $64 \mathrm{mmol} / \mathrm{l}$ was found to be $34.33 \pm 3.52$ (5) and $34 \cdot 87 \pm 3.36$ (5) $\mu \mathrm{mol} / 10 \mathrm{~cm} / 20 \mathrm{~min}$ respectively after control and ethanol diets $(p>0 \cdot 9)$. 
after an ethanol diet. Unlike previous studies, our control diet utilised supplementary fat as a substitute for ethanol because there is evidence that additional dietary carbohydrate enhances sugar absorption. ${ }^{20}$ In addition, it must be emphasised that in this present study, rats were not fasted before experimentation because profound changes in mucosal enzyme activity ${ }^{21}$ and the electrophysiology of the brush border membrane ${ }^{22}$ occur after starvation for even short periods.

We have previously shown that ethanol ingestion by rats is associated with a reduced enterocyte turnover in rat intestine. ${ }^{8}$ Our present results show an increased activity of mucosal lactase in chronic ethanol fed animals. Villus height and enterocyte column size, however, were unaffected by the ethanol diet (Table 1). Kinetic analysis of the galactose absorption data revealed a higher maximum transport capacity $\left(\mathrm{J}_{\max }\right)$ and this was unlikely to be a consequence of an alteration in epithelial metabolism of the transported sugar as galactose is known to be only poorly metabolised by the intestinal mucosa. ${ }^{23}$ Taken together, these results imply the presence of an increased maturity of the enterocyte population on the villus surface in response to ethanol. It is known that enterocytes differentiate functionally during transit becoming mature cells only in the upper portion of the villus. $^{24} 25$ It is therefore possible that ethanol feeding is associated with an increased residence time on the crypt-villus axis resulting in a greater proportion of mature cells on the villus surface.

The similarity of values for apparent $\mathrm{K}_{\mathrm{t}}$ in the intestine of control and ethanol fed rats implies an unchanged binding affinity of each hexose carrier on the brush border membrane.

The phlorhizin insensitive (diffusive) component of galactose absorption was found to be unaffected by ethanol feeding. This result conflicts with the study by Thomson ${ }^{26}$ who found that the passive permeability for glucose of rabbit jejunum was markedly increased after an ethanol diet. A much lower level of alcohol in the drinking solution was used in this present study, however.

The mechanisms by which ethanol may modify enterocyte turnover, lactase activity and galactose absorption are unknown. Changes in lactase activity as well as enterocyte turnover ${ }^{8}$ occur in both upper and lower regions of rat small intestine. Because of the avid absorption of ethanol in the upper gastrointestinal tract, ${ }^{27}$ its luminal concentration would be expected to be much higher in the jejunum compared to the ileum. Our results, therefore, imply a systemic rather than a direct luminal response to alcohol. Previous studies have implicated a hormonal regulation of both intestinal lactase activity ${ }^{28}$ and nutrient absorption ${ }^{29}$ and the response to chronic ethanol feeding may well be mediated by a systemic route.

In conclusion, we have shown clear increases in both active hexose transport and lactase activity following chronic ethanol ingestion. This may be a mechanism by which the small intestine not only adapts to the toxic effects of alcohol but overcorrects for the malabsorption induced by acute ethanol. Whether alcoholics display this response is unknown, although there is some evidence that chronic administration of ethanol does increase glucose absorption in well nourished individuals. ${ }^{30}$ Our study using pair fed rats suggests that sugar uptake should not be impaired in alcoholics fed a nutritionally adequate diet.

\section{References}

1 Beck IT, Dinda PK. Acute exposure of small intestine to ethanol. Effects on morphology and function. Dig Dis Sci 1981; 26: 817-38.

2 Chang T, Lewis J, Glazko AJ. Effect of ethanol and other alcohols on the transport of amino acids and glucose by everted sacs of rat small intestine. Biochim Biophys Acta 1967; 135: 1000-7.

3 Kuo YJ, Shanbour LL. Effects of ethanol on sodium, 30 -methylglucose and $\mathrm{L}$-alanine transport in the jejunum. Am J Dig Dis 1978; 23: 51-6.

4 Wilson FA, Hoyumpa AM. Ethanol and small intestinal transport. Gastroenterology 1979; 76: 388-403.

5 Balaghi M, Neal RA. Effect of chronic ethanol administration on thiamine metabolism in the rat. J Nutr 1977; 107: 2144-52.

6 Lindenbaum J, Lieber CS. Alcohol induced malabsorption of vitamin $B_{12}$ in man. Nature 1969; 224: 806.

7 Lindenbaum J, Lieber CS. Effect of chronic ethanol administration on intestinal absorption in man in the absence of nutritional deficiency. Ann NY Acad Sci 1975; 252: 228-34.

8 Mazzanti R, Jenkins WJ. Effect of chronic ethanol ingestion on enterocyte turnover in the small intestine. [Abstract]. Gut 1984; 25: A1154.

9 Yamada K, Bustamante S, Koldowsky O. Dietaryinduced rapid increase of rat jejunal sucrose and lactase activity in all regions of the villus. FEBS Lett 1981; 129: 89-92.

10 Yamada K, Goda T, Bustamante S, Koldowsky O. Different effect of starvation on activity of sucrose and lactase in rat jejunoileum. Am J Physiol 1983; 244: G449-G455.

11 Debnam ES, Levin RJ. An experimental method of identifying and quantifying the active transfer electrogenic component from the diffusive component during sugar absorption measured in vivo. $J$ Physiol 1975; 246: 181-96.

12 Debnam ES. Effect of sodium concentration and plasma sugar concentration on hexose absorption by rat jejunum in vivo. Further evidence for two transport mechanisms. Pflügers Arch 1982; 393: 104-8. 
13 Debnam ES, Mazzanti R, Jenkins WJ. Effect of chronic ethanol ingestion on galactose absorption and enterocyte turnover in rat jejunum. J Physiol 1985; 364: 82P.

14 Ryle PR, Broillet A, Perrissoud D, Chakraborty J, Thomson AD. A comparative study of the effects of (+)-catechin and 3-Palmitoyl-(+)-catechin on alcoholic fatty liver in the rat. Alcohol Alcoholism 1983; 18: 239-48.

15 Brien JF, Loomis CW. Gas-liquid chromatographic determination of ethanol and acetaldehyde in blood. Clin Chim Acta 1978; 87: 175-80.

16 Dahlqvist A. Method for assay of intestinal disaccharidases. Anal Biochem 1964; 7: 18-25.

17 Lowry OH, Rosebrough NJ, Farr AL, Randal RJ. Protein measurement with the Folin phenol reagent. $J$ Biol Chem 1951; 193: 265-75.

18 Krebs HA, Henseleit K. Untersuchungen uber die Harnstoffbildung im Tierkorper. Hoppe-Seyler's Z Physiol Chem 1932; 210: 33-66.

19 Somogyi M. A new reagent for the determination of sugars. J Biol Chem 1945; 160: 61-8.

20 Diamond JM, Karasov WH. Effect of dietary carbohydrate on monosaccharide uptake by mouse small intestine in vitro. J Physiol 1984; 349: 419-40.

21 Murrary D, Wild GE. Effect of fasting on Na-K-
ATPase activity in rat small intestinal mucosa. Can $J$ Physiol Pharmacol 1980; 58: 643-9.

22 Debnam ES, Thompson CS. The effect of fasting on the potential difference across the brush border membrane of enterocytes in rat small intestine. $J$ Physiol 1984; 355: 449-56.

23 Barry RJC, Dikstein S, Matthews J, Smyth DH, Wright EM. Electrical potentials associated with intestinal sugar transfer. J Physiol 1964; 171: 316-38.

24 Lipkin M. Proliferation and differentiation of gastrointestinal cells. Physiol Rev 1973; 53: 891-915.

25 Smith MW. Expression of digestive and absorptive function in differentiating enterocytes. Ann Rev Physiol 1985; 47: 247-60.

26 Thomson ABR. Effect of chronic ingestion of ethanol on in vitro uptake of lipids and glucose in the rabbit jejunum. Am J Physiol 1984; 246: G120-129.

27 Bode JC. Alcohol and the gastrointestinal tract. Adv Intern Med Pediatr 1980; 45: 1-75.

28 Raul F, Noriega R, Nsi-Emvo E, Doffoel M, Grenier JF. Lactase activity is under hormonal control in the intestine of adult rat. Gut 1983; 24: 648-52.

29 Levin RJ. The effects of hormones on the absorptive metabolic and digestive functions of the small intestine. J Endocrinol 1969; 45: 315-348.

30 Green PHR. Drugs, alcohol and malabsorption. Am J Med 1979; 67: 1066-76. 